
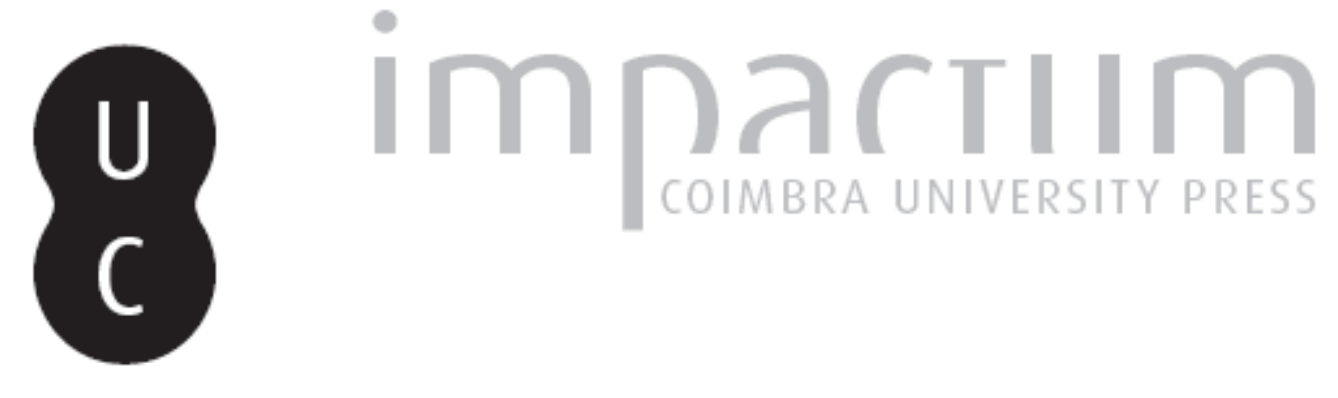

\title{
Elogio de Santiago de Compostela em hexâmetros latinos
}
Autor(es): $\quad$ Urbano, Carlota Miranda
Publicado por: Associação Portuguesa de Estudos Clássicos; Instituto de Estudos Clássicos

URL persistente:

URI:http://hdl.handle.net/10316.2/30367

DOI:

DOI:http://dx.doi.org/10.14195/0872-2110_54_8

Accessed : $\quad$ 26-Apr-2023 15:06:25

A navegação consulta e descarregamento dos títulos inseridos nas Bibliotecas Digitais UC Digitalis, UC Pombalina e UC Impactum, pressupõem a aceitação plena e sem reservas dos Termos e Condições de Uso destas Bibliotecas Digitais, disponíveis em https://digitalis.uc.pt/pt-pt/termos.

Conforme exposto nos referidos Termos e Condições de Uso, o descarregamento de títulos de acesso restrito requer uma licença válida de autorização devendo o utilizador aceder ao(s) documento(s) a partir de um endereço de IP da instituição detentora da supramencionada licença.

Ao utilizador é apenas permitido o descarregamento para uso pessoal, pelo que o emprego do(s) título(s) descarregado(s) para outro fim, designadamente comercial, carece de autorização do respetivo autor ou editor da obra.

Na medida em que todas as obras da UC Digitalis se encontram protegidas pelo Código do Direito de Autor e Direitos Conexos e demais legislação aplicável, toda a cópia, parcial ou total, deste documento, nos casos em que é legalmente admitida, deverá conter ou fazer-se acompanhar por este aviso.

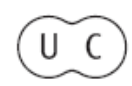




\section{Boletim de \\ Estudos Clássicos}

Associação Portuguesa de Estudos Clássicos

Instituto de Estudos Clássicos

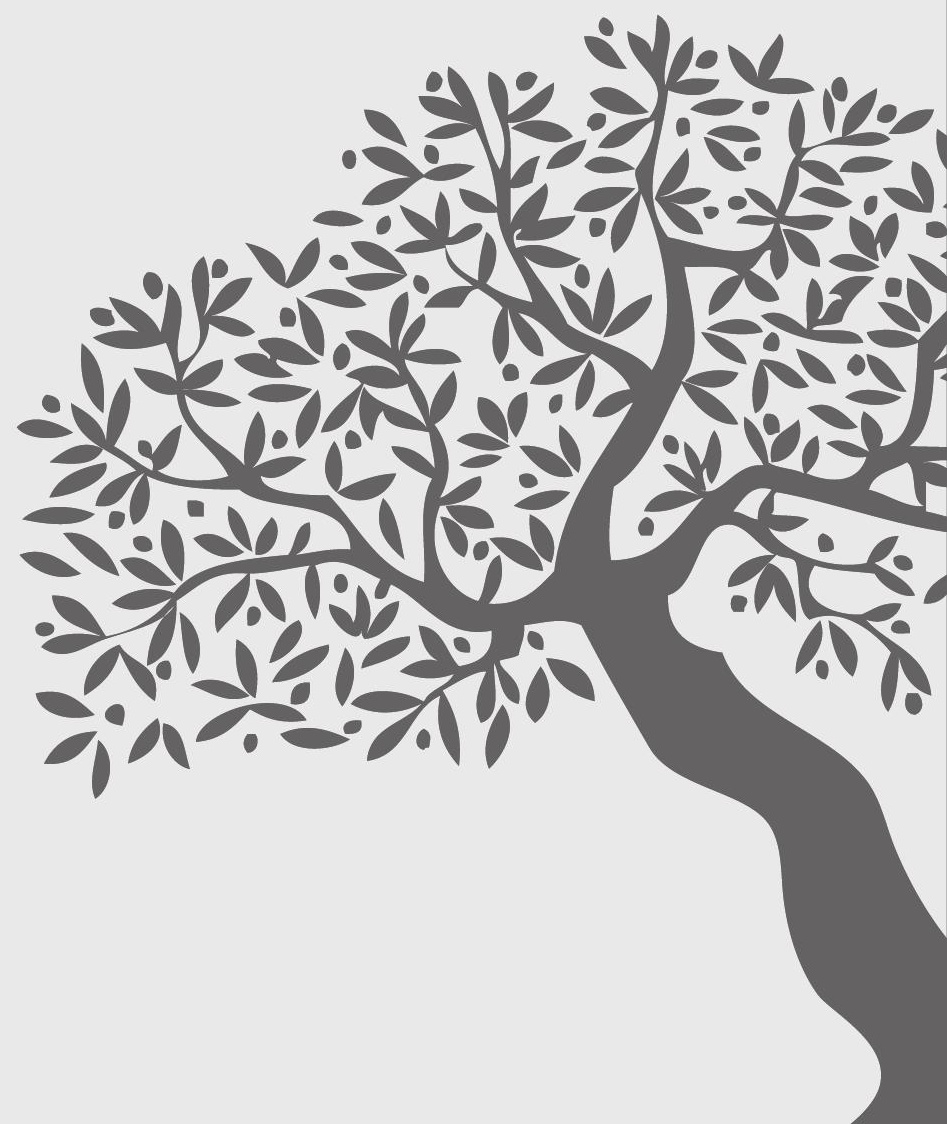

Coimbra

Dezembro de 2010 


\title{
ELOGIO DE SANTIAGO DE COMPOSTELA EM HEXÂMETROS LATINOS
}

\author{
Paciecidos, VII, 206-249; 481-549
}

Desde o séc. XII que cada ano em que o dia 25 de Julho, dia do apóstolo São Tiago, calhe a um Domingo, é considerado um Ano Santo de Jubileu para a catedral de Santiago de Compostela. Este ano de 2010 foi, por isso, 'Xacobeo' e, mais do que o habitual de todos os anos, acorreram ao santuário galego multidões de peregrinos de toda a Europa.

Se exceptuarmos Roma, nenhum santuário medieval na Europa conheceu tamanha longevidade e vitalidade como centro de peregrinação religiosa. E num aspecto supera a própria Roma, pois ostenta rotas determinadas (o 'caminho de Santiago') em que os peregrinos, venham de onde vierem, se reconhecem como 'caminheiros' de Santiago. O sucesso do 'caminho de Santiago' estende-se aos nossos dias, sobretudo depois da década de 70 do séc. passado em que movimentos pacifistas encontraram nele uma representação do seu ideário. Não será por acaso que o Conselho Europeu declarou o Caminho de Santiago como o Primeiro itinerário cultural europeu, em 1987 e mais tarde, em 1993, ele veio a ser reconhecido pela UNESCO como Património Cultural da Humanidade.

A peregrinação, prática religiosa com expressões e cambiantes de significado diversos ao longo da história, no caso do cristianismo regista-se desde as suas origens. Recorde-se, a título de exemplo, a peregrinação de Helena, mãe do imperador Constantino, a Jerusalém, em 326, ou o célebre relato da peregrinação de Egéria nos finais do séc. IV. A peregrinação cristã começou por ser aos lugares onde Jesus Cristo tinha vivido, mas estendeu-se depois aos lugares onde estavam as relíquias dos apóstolos, como é o caso de Roma, ou de Compostela.

O fenómeno da peregrinação conheceu especial dimensão durante a Idade Média e, apesar da contestação que lhe foi movida pelos movimentos reformistas, o desenvolvimento da piedade popular garantiu a continuidade a esta e outras práticas da devotio moderna, como o culto dos santos, das 
relíquias, etc... A devotio moderna, com efeito, contribuíra para a renovação do significado espiritual da peregrinação, que, não podendo realizar-se numa viagem geográfica, tomava naquela espiritualidade o significado metafórico da vida espiritual do homem na terra. Exemplo do valor operativo da peregrinação no séc. XVI é o empenho de Inácio de Loyola e dos companheiros em peregrinar à terra Santa, o que não chegaram a concretizar. A importância da imaginação e dos sentidos na prática dos Exercícios Espirituais, mostram, por outro lado, o valor da peregrinação 'interior'. O exercitante é convidado a imaginar e a fazer a 'composição do lugar' não só dos espaços onde Jesus Cristo viveu, mas também do ambiente humano que o rodeia de modo a contemplar a sua vida e a conhecê-lo.

Assim sendo, compreende-se perfeitamente por que razão a peregrinação faz parte do tirocínio do jovem membro da Companhia de Jesus.

No poema épico Paciecidos (Bartolomeu Pereira, Coimbra, 1640) a que em números anteriores nos referimos e cujos passos aqui temos vindo a traduzir, a narrativa da vida do herói principal, feita em registo autobiográfico analéptico, seguindo as normas do modelo épico homérico-virgiliano, passa também por uma peregrinatio ad locum sancti Iacobi. Durante o noviciado em Coimbra, no Colégio de Jesus, Francisco Pacheco peregrinou juntamente com um companheiro até Santiago de Compostela:

Então recebo a ordem de, juntamente com um companheiro, me pôr a caminho por vilas e cidades; levo o alforge de peregrino dependurado e no cajado bem torneado apoio o passo. ${ }^{1}$

E, de imediato, o poeta coloca na boca do herói uma digressão que apresenta resumidamente a história do santuário galego (fanum gallaecum) e a sua importância na Europa cristã. Tendo em conta os múltiplos objectivos do Paciecidos, esta é uma daquelas digressões que exemplificam a aliança entre os seus objectivos edificantes e didácticos.

Nos confins extremos da Galiza ergue-se um grande santuário, sumptuoso graças à beneficência real, e assinalável pelo poder do seu patrono. Os antigos hispanos o edificaram para Santiago, e os seus descendentes o conservam com igual piedade.

1 Tunc socius comitatus iter, perque oppida et urbes/ ferre uiam iubeor; peregrino pendula collo/ It pera, et tereti baculo uestigia firmo. (VII, 206-209) 
A poderosa direita de Afonso o fundou, e Ramiro, regressando de uma grande vitória sobre os Mouros, lhe trouxe e consagrou como voto imortal os bens alcançados, o ouro e espólios do triunfo, o orgulhoso inimigo, as armas e os estandartes vencidos.

Os reis que se seguiram-dizem- rivalizaram para erguer aos céus este santuário e enriqueceram-no com largo património. Diante dos altares que lhes estão consagrados, pendem das elevadas molduras do tecto trezentas chamas em lâmpadas de prata que as cordas a custo conseguem suportar. As torres, enormes, a custo comportam os sinos, que jazem no chão pois, quando tocados, levavam muitas vezes à loucura, provocavam partos antes do tempo e faziam ruir mesmo edifícios robustos.

Aqui acorrem as cidades da Lysia, aqui as multidões da raça dos Iberos, Aqui todos os da Gália, e os da Flandres, famosa pelo canto, os povos da Itália, os dois braços do Reno aqui vêm e cumulam de dons os altares sagrados.

Diz-se até que, aqueles que em vida não vieram suplicantes a este templo, depois da hora das sombras da morte, aqui hão-de vir oferecer os seus dons aos santos bemaventurados, percorrendo a via láctea que nas suas estrelas resplandece na noite serena e traça no céu um longo caminho.

Sob o templo estende-se uma vasta galeria encerrada em sombras, secreta morada onde se diz que estão guardadas num sepulcro as preciosas relíquias de São Tiago.

A nenhum homem é permitido transpor a sua entrada sagrada, nem visitar ou percorrer os seus caminhos. Apenas, de longe, suplicam as suas graças, cobrem de beijos o limiar e regressam a suas casas com figuras de Santiago nos chapéus, o bastão ao ombro e, a enfeitá-los, as conchas reluzentes. ${ }^{2}$

2 Est fanum extremis Gallaecum in finibus ingens/ regnatum donis opulentum, et numine diui/ conspicuum; ueteres illud posuere Jacobo/ Hispani; seruantque aequa pietate minores./ Hoc primum Alfonsi dextra imperiosa locauit,/ atque inde ingenti Maurorum e caede Ramirus/ adueniens, auroque auctus spoliisque triumphi/ dona ferens, templo uotum immortale, superbos/ atque hostes, captosque enses, et signa dicauit./ Inde poli ut ferrent superos delubra sub axes,/ conspirasse alios reges, et 
No caminho para Santiago, a partir de Coimbra, onde fazia o noviciado, Francisco Pacheco e o seu companheiro passam por Ponte de Lima, terra natal do herói do poema. Esta passagem proporciona um encontro com um jovem caçador que era ainda seu parente e que o põe ao corrente dos trágicos acontecimentos que atingiram a sua família. $\mathrm{O}$ episódio, que se estende por 232 hexâmetros, relata uma desavença familiar, a morte do pai de Pacheco, o auxílio prestado à família pelo tio, e a transição para o plano narrativo da peregrinação faz-se com uma reflexão do herói e uma cena de pacificação. Os três jovens acabam por salvar dos cães caçadores uma corça com as suas crias.

A seguir a este episódio, a narrativa analéptica prossegue com a peregrinação que se encontra já na sua meta. Os peregrinos chegam à cidade no dia da festa de Santiago e Francisco Pacheco descreve, desde a grandiosidade da catedral à magnificência da liturgia, passando pela riqueza da música dos festejos. Concede ainda alguns versos à oração que os companheiros fizeram e à consolação espiritual experimentada pelos peregrinos. O passo conclui o Canto VII com as palavras que Francisco Pacheco dirige a Galiza e ao seu santuário, eivadas de sentido místico.

Assim que terminou a nossa conversa com este jovem, logo prosseguimos viagem, e eis que Compostela, sublime na sua mole soberba, na catedral e nas elevadas muralhas, nos

munere largo/ ditauisse ferunt. Horum de nomine sacras/ ante aras, tercentum ignes laquearibus altis / argento inclusi, pendent; uix lampada funes/ sustentare queunt; magnae uix cymbala turres/ accipiunt; decisa iacent, nam pulsa cerebro/ saepe dabant furias, conceptis foetibus ortus/ ante diem, domibusque graues traxere ruinas. /Huc Lysisae properant urbes, huc gentis Iberae/ turbae adeunt, Gallique omnes, et Flandria cantu/ insignis, populique Itali, Rhenusque bicornis/ confluit, et donis altaria sacra frequentant./ Namque ferunt, uiui qui non haec templa petentes/ inuisunt, post fata illuc et funeris umbras/ uenturos, munusque istud praestare beatis/ lacte uiam stellisque albam, quae nocte serena/ fulgurat, et longo designat tramite caelum./ Ingens sub templo fornix, et claustra per umbras/ Magna iacent, caecaeque domus, queis magna Iacobi/ ossa sepulcrali fama est in sede latere. / Nulli fas hominum sacratum insistere limen; / est uidisse nefas, nec eundi peruius usus;/ e longe ueniam exorant, atque oscula figunt/ liminibus; redeuntque domos, uariasque galeris/ Iacobi effigies addunt, humerosque bacillis/circumdant, conchisque super fulgentibus ornant. (VII, 209-244) 
ostenta o cume cercado de torres e nos concede, propícia, a meta suprema e o fim dos trabalhos do caminho percorrido.

Foi no dia solene que Roma designou e consagrou especialmente a São Tiago todos os anos. Quando chegámos à praça e foi possível alcançar a entrada, já o bispo insigne, com o báculo e a mitra, de vestes venerandas, presidia à liturgia. Rodeavam-no sete cónegos com as tiaras púrpuras e uma multidão de mais de cem que serviam o altar e cantavam na sagrada catedral. Todos eles, carregados de ouro e pedras preciosas, ornados nas suas vestes, uns seguravam alfaias e as maças de prata, outros queimavam incenso. Mil chamas perfumam os altares e as alfaias sagradas, e ressoam mil cânticos pelas naves imensas; responde-lhes o órgão em aplauso festivo. Replicam as cítaras, o bronze redobra os seus sons em cadência, os tambores juntam alegre ressoada e, do alto das torres respondem finalmente os sinos.

Entretanto, nós, vamo-nos ajoelhando por diversos sítios do grande santuário, suplicando auxílio, e invocamos com as nossas preces o guia dos Hispanos, Tiago, o guerreiro, para que nos conceda, miseráveis, a arma na luta contra os vícios, para que aos seus dê o escudo fiel e o elmo, e forneça a espada fulminante, e para que os corações inteiramente comunguem com Santiago.

O triunfo que outrora concedeu aos Hispanos, vencido Maomé, nos conceda agora contra o rei dos Infernos, acumule os nossos troféus e conceda a vitória às nossas lutas.

E com esta oração experimentamos divinos sentimentos, um coração acalentado pelo céu e, pouco a pouco, a graça de Deus. É impossível dizer tudo o que ali nos foi revelado.

Vós, que habitais o céu, apenas vós podeis contar as consolações de alma que as relíquias e os divinos restos mortais de Santiago inspiram na alma dos que aqui vêm e as chamas com que lhes aquecem o peito. ${ }^{3}$

3 Tun iuuenem extremum affati, contendimus ultro/ Ire uiam, donec se Compostella superbis/ molibus elatam, temploque et moenibus altis / turrigerum caput ostendit, metamque supremum/ laeta dedit, ceptosque uiae finire labores./ Illa dies solemnis erat quam Roma quotannis/ Iacobo sacram dixit, propriamque 
E ao despedir-se da cidade dirige à Galiza palavras de louvor. Os tópicos habituais do louvor da terra pela sua fertilidade, abundância de bens ou os heróis que a ilustraram, servem aqui para ceder a primazia da glória da Galiza a um motivo que o poeta quer afirmar superior. A posse das relíquias do apóstolo é razão muito maior para que glorifique a Galiza.

Ó Galiza, terra mais que todas bem-aventurada, não porque os hispanos têm em ti nobres antepassados, nascidos do teu sangue, não porque tens uma terra fértil, ou pela riqueza dos teus campos, nem porque o rio com as suas águas calmas e os seus peixes te rodeia e reconhece como Rainha. São dons magníficos, certamente, mas quanto mais não se eleva a tua glória porque Tiago, tendo vivido nos templos de Jerusalém, na soberba fortaleza da nobre Sião, e em Roma, o que há de mais magnífico no mundo, entre todas as terras apenas a ti escolheu para morada, te concedeu a glória do seu sepulcro e, para sempre, te acrescenta novas honras. ${ }^{4}$

dicauit/Dumque forum, templique aditus et claustra subimus/ iam baculo insignis, mitraque et ueste uerendus/ antistes sacro adstabat, septemque tiaris/ purpurei circum patres, et maxima centum/turba ministrantum, sacraque in sede canentum/ cuncti auro gemmisque graues, pallaque decori / ingens argentum manibus, clauasque tenebant./ Thura alii incendunt, arasque et sacra uaporant/ mille ignes; et mille sonant per grandia cautus/ atria ; festiuo responsant organa plausu./ Ingeminant citharae, sonitus curuatur ahenus/ ad numerum, laetos dant tympana pulsa boatus,/ extremumque altis respondent turribus aera./ Nos tamen interea delubra ingentia circum/ submissi imploramus opem, precibusque ciemus/ ductorem Hispanum, bellatoremque Iacobum/ det miseris hastam uitiorum in bella, fidelem/ det clypeum galeamque suis, ensemque ministret/ fulmineum, totumque inspirent corda Iacobum; / quosque olim Hispanis uicto et Mahomete triumphos/ hos nobis Stygio det tandem e rege trophaea/ accumulet, palmasque ferat melioribus ausis./ Haec prece diuinos haustus, afflataque caelo/ pecctora, et aethereos sensim sub corde fauores/ experti; nec cuncta licet monstrata profari./ Vos, o caelicolae, solum numerare potestis,/ quas ibi reliquiae, diuinique ossa Iacobi/ inspirare animis uenientum , atque addere menti/ delicias, quantasque solent incendere flammas./

${ }^{4} \mathrm{O}$ felix una ante alias, Gallaecia terras,/ non equidem , antiquos ad te quod sangunis ortus/ Hispani referant proceres, seu diuitis arui/ pingue solum teneas, uel quod te piscibus aequor/ reginam agnoscens placidis circumfluat undis./ Magna quidem haec, surgit maior sed gloria, maior/quod te Iacobus terris magis omnibus unam/ posthabitis Solymae templis, claraeque Sionis/ arce superbifica, Romaque, et 
Lançando o leitor numa espécie de visão onírica, o poeta associa a magnificência da escadaria da catedral e o valor espiritual que ela simboliza, à escada que o patriarca Jacob viu em sonhos. Quando, a caminho de Haram, Jacob pernoitou num lugar chamado Luz, tomando para travesseiro uma pedra, teve um sonho em que viu uma escada que unia o céu e a terra, por onde subiam e desciam os anjos. No cimo da escada estava Deus que lhe falou. Quando despertou, Jacob pegou na pedra que lhe serviu de travesseiro, ergueu-a como monumento e derramou óleo sobre ela, consagrando aquele lugar, que se chamava Luz, com o nome de Betel. As palavras que o poeta coloca na boca do herói resultam provavelmente de uma associação, evidente no texto latino, entre o nome do patriarca Jacob e o de Tiago (Jacobus), mas talvez resultem também de alguma representação do Patriarca no relevo da fachada, o que não conseguimos averiguar. Em todo o caso, não podemos esquecer que a fachada que Francisco Pacheco ou Bartolomeu Pereira terão conhecido, não era ainda a da grandiosidade barroca que hoje lhe conhecemos. $^{5}$

A escadaria, por sinédoque a catedral, é espaço privilegiado de ligação entre Deus e os homens, como o exprimem os últimos versos do canto VII.

Aqui, nesta antiga pedra, há muito dorme uma longa noite o filho de Isaac, e a formosa mansão do céu revela aquela escada que durante a noite Jacob contemplou, sobre uma pedra fria, entre as sarças agrestes, onde lhe foi possível deitar-se. Se aquela máquina pôde sustentar o leve exército de anjos que a subiam e desciam, não suportou os passos do Rei dos Céus; é do cimo desta elevada escadaria onde permanece, que ele vela pelo género humano. Esta escada, Deus e os homens a sobem, ela une ao céu a terra e a raça humana. É realmente sagrado este lugar! É a própria porta resplandecente do céu, a casa de Deus, a pedra onde (Jacob) derramou óleo. Pela presença de Deus, esta pedra se transforma em suave caminho para os céus.

quidquid in orbe/ est magnum, incoluit, celebremque hac sede sepulcri/ esse dedit, semperque nouos acquirit honores. (VII, 519-529)

5 À catedral românico-gótica foi acrescentada por Fernando de Casas em 1738 a fachada barroca, apontada como um dos exemplos inspiradores das chamadas 'fachadas de retábulo'. Cfr. Sutton, Ian, História da Arquitectura no Ocidente, Verbo, 2004, 221-222. 
Assim falei eu, primeiro, e depois o meu companheiro, com palavras sentidas, acrescenta muitas outras coisas, louvando a cidade e a catedral. Finalmente, cumpridas as nossas devoções diante do altar do Santo, voltamos para os melodiosos salgueiros nas margens do Mondego e tomamos o caminho até aos campos e à cidade de Hércules. ${ }^{6}$

E com estes versos termina o canto VII e se estabelece de novo a ligação com a narrativa analéptica em que Francisco Pacheco retoma os anos de estudo em Coimbra. ${ }^{7} \mathrm{O}$ passo, além de se inscrever no conjunto de elogios de cidades que enriquecem o longo poema dotando-o com diversidade e uariatio de motivos, justifica-se coerentemente com a narrativa autobiográfica do herói e, pela natureza predominantemente espiritual dos motivos nele tratados, serve com eficácia o tema central do poema: a celebração do martírio. Com efeito, trata-se da narrativa de uma experiência espiritual do jovem herói épico em peregrinação ao túmulo do primeiro dos apóstolos que sofreu o martírio. Logo de seguida, no canto VIII, depois de numa dúzia de versos resumir quatro anos de estudo, Francisco Pacheco lança-se numa descrição desenvolvida daquilo que foi para ele conceber o sonho e o desejo cada vez mais intenso de partir para o Oriente, onde viria a morrer mártir.

CARLOTA MIRANDA URBANO

6 Hic saxo Isacides longa iam nocte uetusto/ obdormit, scalamque poli tecta aurea reddunt/ cui nunquam, media uidit quam nocte Iacobus/ Rupe super gelida, atque horrentibus undique dumis/ ante licet posuisse; leues ea machina caeli/ descendentum acies, ascendentumque tueri/ si ualui, numquam superi uestigia Regis/ sustinuit; scalae accliuis de culmine summo/ constitit, opperiens humanae examina gentis./ Hanc Deus, hanc homines subeunt; haec iungit Olympo/ terrasque humanumque genus; uere locus iste/ terribilis; non ille aliud, nisi candida caeli/ porta, domusque Dei, lapides, perfusaque Lusae/ saxa óleo; praesente Deo, uia mollis ad astra/ fit saxum. (VII, 530-549)

7 Neste e noutros passos designada como 'cidade de Hércules'. Os humanistas identificavam Coimbra com a zona do extremo ocidente dominada por Gerião (cujo gado Hércules devia reunir para cumprir um dos seus trabalhos). 